\title{
The Course of Activities in Daily Living: Who Is at Risk for Decline after First Ever Stroke?
}

\author{
Roderick Wondergem $^{\mathrm{a}, \mathrm{b}, \mathrm{d}}$ Martijn F. Pisters ${ }^{\mathrm{a}, \mathrm{b}}$ Eveline J. Wouters ${ }^{\mathrm{a}} \mathrm{d}$ \\ Nick Olthof ${ }^{a, b}$ Rob A. de Bie ${ }^{e}$ Johanna M.A. Visser-Meily ${ }^{c}$ Cindy Veenhof $^{a}, b$ \\ ${ }^{a}$ Center for Physical Therapy Research and Innovation in Primary Care, Julius Health Care Centers, ${ }^{b}$ Physical \\ Therapy Research, Department of Rehabilitation, Nursing Science and Sport, Brain Center Rudolf Magnus, \\ and ${ }^{\mathrm{C} C e n t e r}$ of Excellence for Rehabilitation Medicine, Brain Center Rudolf Magnus, University Medical Center \\ Utrecht, Utrecht, ${ }^{d}$ Department of Health Innovations and Technology, Fontys University of Applied Sciences,

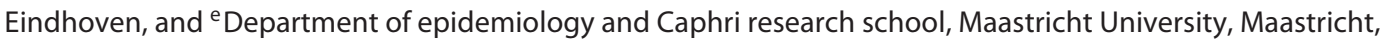 \\ The Netherlands
}

\section{Key Words}

Stroke - Activities of daily living - Decline - Risk factors ·

Meta-analysis $\cdot$ Systematic review

\begin{abstract}
Background: Stroke is not only an acute disease, but for the majority of patients, it also becomes a chronic condition. There is a major concern about the long-term follow-up with respect to activities of daily living (ADL) in stroke survivors. Some patients seem to be at risk for decline after a first-ever stroke. The purpose of this study was to determine the course of ADL from 3 months after the first-ever stroke and onward and identify factors associated with decline in ADL. Methods: A systematic literature search of 3 electronic databases through June 2015 was conducted. Longitudinal studies evaluating changes in ADL from 3 months post stroke onward were included. Cohorts including recurrent strokes and transient ischemic attacks were excluded. Regarding the course of $A D L$, a meta-analysis was performed using random-effects model. A best evidence synthesis was per-
\end{abstract}

formed to identify factors associated with decline in ADL. Results: Out of 10,473 publications, 28 unique studies were included. A small but significant improvement in ADL was found from 3 to 12 months post stroke (standardized mean difference (SMD) $0.17(0.04-0.30)$ ), which mainly seemed to occur between 3 and 6 months post stroke (SMD 0.15 (0.05$0.26)$ ). From 1 to 3 years post stroke, no significant change was found. Five studies found a decline in ADL status over time in $12-40 \%$ of patients. Nine factors were associated with ADL decline. There is moderate evidence for being dependent in ADL and impaired motor function of the leg. Limited evidence was found associated with insurance status, living alone, age $\geq 80$, inactive state and having impaired cognitive function, depression and fatigue with decline in ADL. Conclusion: Although on an average patients do not seem to decline in ADL for up to 3 years, there is considerable variation within the population. Some modifiable factors associated with decline in ADL were identified. However, more research is needed before patients at risk of deterioration in ADL can be identified.

(c) 2016 The Author(s) Published by S. Karger AG, Basel

\section{KARGER}

E-Mail karger@karger.com www.karger.com/ced

\section{The Author(s) \\ Published by S. Karger AG, Basel \\ Karger \\ open access}

This article is licensed under the Creative Commons AttributionNonCommercial-NoDerivatives 4.0 International License (CC BYNC-ND) (http://www.karger.com/Services/OpenAccessLicense). Usage and distribution for commercial purposes as well as any distribution of modified material requires written permission.
Roderick Wondergem, MSc, PT

Center for Physical Therapy Research and Innovation in Primary Care and Brain Center Rudolf Magnus, University Medical Center Utrecht, Room W01.121 PO Box 85500, NL-3508 GA Utrecht (The Netherlands)

E-Mail r.wondergem@fontys.nl 


\section{Introduction}

Advances in the acute medical treatment of stroke have resulted in improved survival rates during the last few decades. Stroke is not only an acute disease, but for the majority of patients, it also develops into a chronic condition. A growing number of people live with the consequences of stroke, resulting in an expected 19\% increase in the global stroke burden in the next 2 decades [1-4].

In 2011, Langhorne et al. [5] launched a hypothetical functional recovery model after stroke, postulating that recovery of body functions and activities reaches a plateau phase between 3 and 6 months post stroke. After 6 months from stroke, it is hypothesized that some patients decline, while on average patients remain stable or improve. It, however, remains unclear whether the hypothesized functional recovery model can be confirmed based on the existing literature.

Integrated stroke services have been developed to provide multidisciplinary, coordinated care during the first months, when acute care and rehabilitation are prominent [6]. However, a major concern is poor long-term follow-up with respect to problems in activities of daily living (ADL), an important determinant for social reintegration [7].

Therefore, the aim of this systematic review is [1] to determine the course of ADL in the period between 3 months and onward following first-ever stroke and [2] to identify factors associated with decline in ADL. Early identification of patients at risk for decline in ADL might enable professionals to provide effective support and monitoring to these patients to prevent decline.

\section{Methods}

\section{In- and Exclusion Criteria}

Studies eligible for this review met the following inclusion criteria: (1) evaluating changes in ADL (domains $\mathrm{d} 4$ mobility and $\mathrm{d} 5$ self-care of the ICF model without moving around with transportation d470-d489) [8] after the first-ever clinical conformed focal neurological deficit due to cerebrovascular disease over a period of at least 6 months from 3 months post stroke, (2) age $\geq 18$ years, (3) peer-reviewed full text publications published in English, German or Dutch. Studies that included patients with transient ischemic attacks, subarachnoid hemorrhage or subdural hematoma were excluded. In cases of multiple publications on the same cohort study presenting different information, reporting on different factors associated with decline in ADL or presenting results after different follow-up periods, all publications were included. However, multiple publications on the same cohort study were considered as one unique cohort study if the inclusion period of patients was equal or overlapped.

\section{Literature Search}

The review was conducted following the recommendations of the statement Preferred Reporting Items for Systematic Reviews and Meta-Analyses [9]. The literature was searched until June 2015 within PubMed (1966), EMBASE (1980) and CINAHL (1982). The search strategy was formulated in PubMed (online suppl. table I; for all online suppl. material, see www.karger.com/ doi/10.1159/000451034) and adapted for use in other databases. It consisted of 3 components: (1) stroke (adapted from Veerbeek et al. [10]), (2) longitudinal cohort studies (following the recommendation for search strings of the Cochrane collaboration) and (3) ADL. Reference lists of included publications and relevant reviews were screened for possible additional relevant publications by one reviewer (R.W.).

\section{Selection Procedure}

The study selection was performed by 2 independent reviewers (R.W. and N.O.) in 2 steps: (1) title and abstract and (2) relevant full text reports. Disagreements were resolved by discussion. If agreement was not achieved, a third reviewer (M.F.P.) was consulted.

\section{Methodological Quality}

Methodological quality of included publications was independently assessed by 2 reviewers (R.W. and N.O.) using the Quality in Prognosis Studies (QUIPS) tool for potential risk of bias (online suppl. table II) [11]. The QUIPS tool assesses 6 domains: (1) study participation, (2) study attrition, (3) prognostic factor measurement, (4) outcome measurement, (5) study confounding and (6) analysis and reporting. Item 5 was not rated because this review does not focus on causality between a single prognostic factor and outcome. The other domains received an overall judgment of 'high', 'moderate' or 'low' risk of bias based on the items within the domains. Publications that scored 'high' for risk of bias on at least one domain were considered low quality. Differences in scoring between the 2 reviewers were discussed. If no consensus was reached, a third reviewer (M.F.P.) was consulted.

\section{Data Extraction}

One reviewer (R.W.) extracted the following information from the included publications: unique studies, number of publications per study, authors, year of publication, setting, year of recruitment, inclusion and exclusion criteria, outcome measures, time points of follow-up, ADL outcome for the different time points, associated factors and percentage of the population who declined in ADL. When only dichotomized, ordinal or visually presented data were available for ADL outcome at the different time points, the authors were requested to provide the number of subjects, mean and SD.

\section{Data Analyses}

Quantitative analyses were performed if at least 3 high quality studies included data on the same time course using Review Manager 5.3 (RevMan. Copenhagen: the Nordic Cochrane Centre, The Cochrane Collaboration, 2008). Time courses from 3 to 12 months post stroke and from 12 months to long-term follow-up were analyzed. Sub-analyses were performed if the data in the included publications were available from 3 to 6 months and from 6 to 12 months post stroke. The means and SDs of the follow-up measurements or the change in scores between both follow-up measurements with the SD were converted to a standardized mean differ- 
Table 1. Level of evidence for associations with decline in ADL

\begin{tabular}{ll}
\hline Level of evidence \\
\hline Strong & $\begin{array}{l}\text { Consistent significant findings in at least } 2 \text { high- } \\
\text { quality studies }\end{array}$ \\
\hline Moderate & $\begin{array}{l}\text { Consistent significant findings in one high- } \\
\text { quality study and at least one low-quality study }\end{array}$ \\
\hline Limited & $\begin{array}{l}\text { Consistent significant findings in one high- } \\
\text { quality study or consistent findings in at least } \\
\text { 3 low-quality studies }\end{array}$ \\
\hline Conflicting & $\begin{array}{l}\text { Conflicting significant findings in high quality } \\
\text { studies (i.e., }<75 \% \text { of the studies reported } \\
\text { consistent findings) }\end{array}$ \\
\hline No evidence & No high quality studies could be found \\
\hline
\end{tabular}

ence (SMD) score, and the 95\% CI was calculated. Pooling was performed using a random-effects model. Changes over time in ADL were considered small if the SMD was $<0.2$, moderate if the $\mathrm{SMD}$ was $0.2-0.8$ or high if the $\mathrm{SMD} \geq 0.8$ [12]. If both performance-based data and self-reported data were provided, performance-based data were used. The data of the Barthel Index were used over other data [13]. $\mathrm{I}^{2}$ was used to test heterogeneity between studies. The $\mathrm{I}^{2}$ was considered to be low $(\leq 25 \%)$, moderate (26$50 \%)$ or high (>75\%) [14]. Sensitivity analyses were performed using both high and low quality studies.

Because it was impossible to perform a quantitative analysis for factors associated with decline in ADL, a best evidence synthesis (BES) was performed. The BES consists of 5 levels of evidence (strong, moderate, limited, inconsistent and no evidence). Conclusions were based on the number of studies evaluating the factor, consistency of results and methodological quality (table 1) [15]. When the results of univariate analyses were available, these were used in the BES; otherwise, the estimates of multivariate analyses were used.

In case of multiple publications based on the same cohort study (e.g., data from Orebro study, South London Stroke Register, NOMASS-study and FuPro study), we used the results of the publication in the quantitative or qualitative analyses with (1) the highest quality, (2) the longest follow-up period, (3) the largest cohort or (4) reported results of univariate analyses instead of associations of multivariate analyses.

\section{Results}

The search strategy yielded 10,473 publications. A flow-chart is presented in figure 1. In total, 28 unique studies were included, based on 36 publications [13, 1650] that fulfilled all selection criteria. Six studies recruited populations from a rehabilitation setting $[18,19,29,34$, $40]$, FuPro study $[13,38,45,46]$ and the other studies included hospital-based populations. An overview of the study characteristics is presented in online supplementary table III. The main reason for exclusion was the absence of follow-up measurements over a period of at least 6 months from 3 months post stroke.

\section{Methodological Quality}

In total, 20 [16, 20, 24-32, 34, 35, 38-41, 43-45] of the 36 publications were rated as high quality (online suppl. table IV). The main reason for downgrading the quality of a study was a high risk of bias in the study attrition domain $[13,17-19,21,33,42,46-49,51]$. In $87.1 \%$ of the 170 methodological items, there was agreement. In all cases, consensus was reached after discussion between the 2 reviewers.

\section{Changes in ADL Status Over Time}

The results showed a small but significant improvement (SMD $0.17(0.04-0.30), \mathrm{p}<0.05, \mathrm{I}^{2}=67 \%$ ) in ADL from 3 to 12 months (fig. 2a). The sub-analysis revealed that this improvement mainly occurred between 3 and 6 months. In this period, a small but significant improvement in ADL was found (SMD $0.15(0.05-0.26), \mathrm{p}<0.05)$ with low to moderate heterogeneity $\left(\mathrm{I}^{2}=29 \%\right.$; fig. $\left.2 \mathrm{~b}\right)$. The sub-analysis from 6 to 12 months showed no significant improvement in ADL (fig. 2c) with moderate to high heterogeneity (SMD $0.07(-0.06$ to 0.20$), \mathrm{p}=0.28, \mathrm{I}^{2}=61$ ). Sensitivity analyses including both low and high quality studies showed similar results with high heterogeneity (online suppl. table V).

For the analysis from 12 months to long-term followup, 2 low quality studies $[17,48]$ and 1 high quality study [45] were available. The data until 3 years follow-up were used. Within this time period, a non-significant decline in ADL was observed with low heterogeneity (SMD -0.02 ( -0.08 to 0.05$), \mathrm{p}=0.58, \mathrm{I}^{2}=0 \%$; fig. $2 \mathrm{~d}$ ).

The proportion of the population that declined, maintained or improved in ADL was reported within 5 studies $[28,38,42,50]$ and FuPro study $[48,49]$ (table 2). These studies reported that between 12 and $40 \%$ of the study population declined in ADL in the period between 3 months post stroke and long-term follow-up. However, within these studies, different cutoff points, outcome measures and follow-up periods were used.

\section{Factors Associated with ADL Decline Over Time}

Researchers described a total of 9 factors that were associated with decline in ADL among 5 unique studies [20, $35,42,45,49]$. Moderate evidence was found for 'being dependent in ADL' $[45,49]$ and 'impaired motor function of the leg' [42, 45]. Limited evidence was found for 'Medicaid/having no insurance' [20], 'living alone' [45], 
Fig. 1. Screening for eligibility. SLSR = South London Stroke Register; TIA = transient ischemic attack; SAH = subarachnoid hemorrhage.

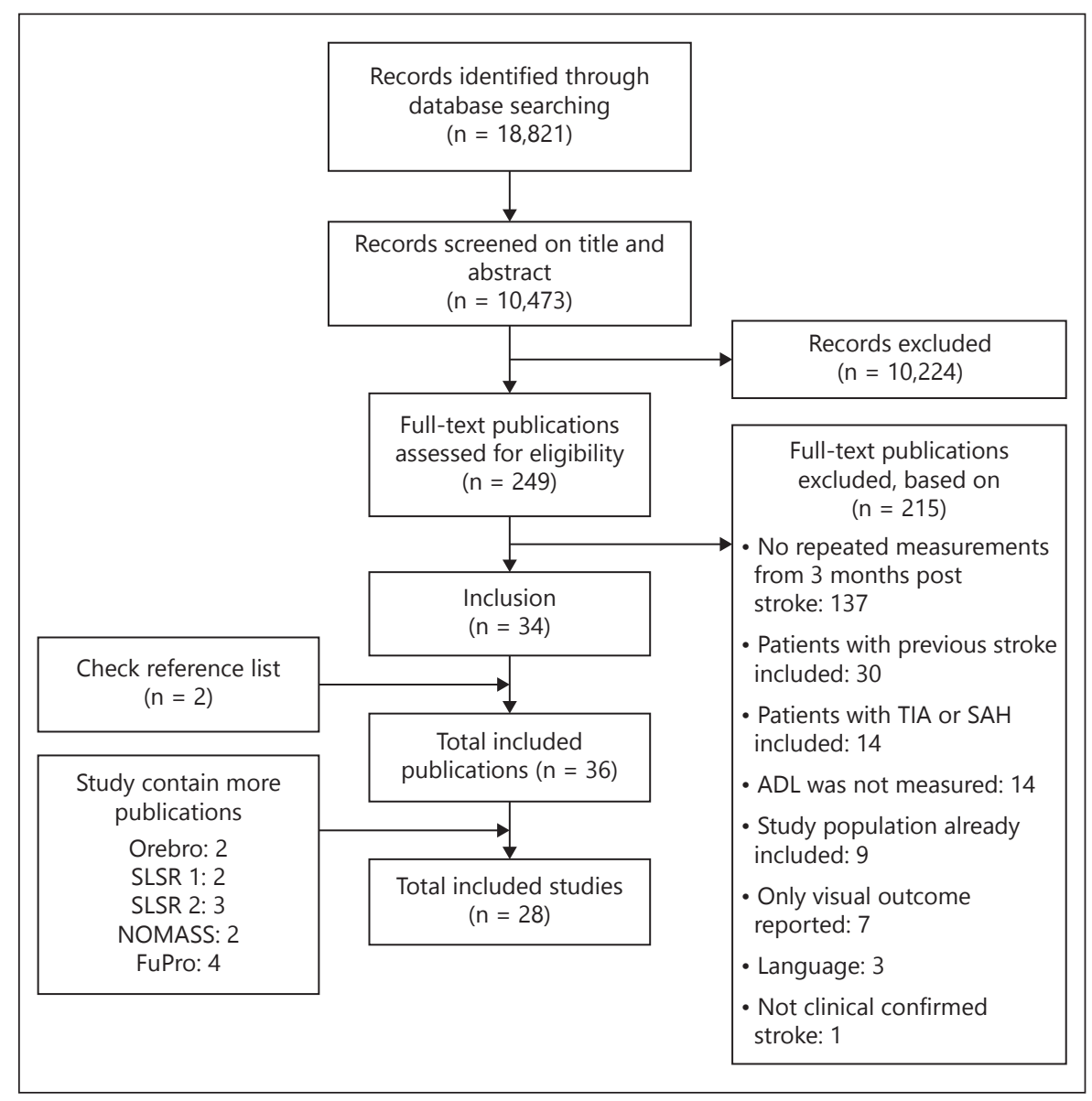

'age $\geq 80$ ' [35], 'being inactive' [45], 'impaired cognitive function' [45], 'presence of depression' [45] and 'presence of fatigue' [45].

\section{Discussion}

In this study, the course of ADL in the period between 3 months after the first-ever stroke and longer term was explored as well as factors associated with decline in ADL status. The results from this review showed a small, but statistically significant improvement in ADL between 3 and 12 months post stroke. However, this improvement mainly occurred between 3 and 6 months, and the results also suggest that ADL status seems to remain stable from 1 to 3 years post stroke.

\section{Changes in ADL Status Over Time}

The results are in accordance with the hypothesized model of Langhorne et al. [5], illustrating that ADL recovery seems to reach a plateau phase somewhere between 3 and 6 months post stroke. Although the results suggest that ADL status remains fairly stable after 6 months post first-ever stroke, these results might be biased. The studies used in the meta-analyses included populations recruited from hospital-based settings, severe subpopulations recruited from hospital-based settings and studies using a study population recruited from a rehabilitationbased setting. It can be hypothesized that the more severe hospital populations as well as the rehabilitation populations will have a different course in ADL status over time. Also, the different types of ADL outcomes measures used in the included studies might have influenced the results. The majority of the studies used the Barthel Index; however, mobility measures were also commonly used. The responsiveness to change might be different for mobility measures, since these do not include self-care items. However, analyzing a more homogenous population (using only studies that recruited the study population from a hospital setting, using instruments that measure the full spectrum of $\mathrm{ADL}$ ) showed comparable results (online suppl. fig. 1a and b). 


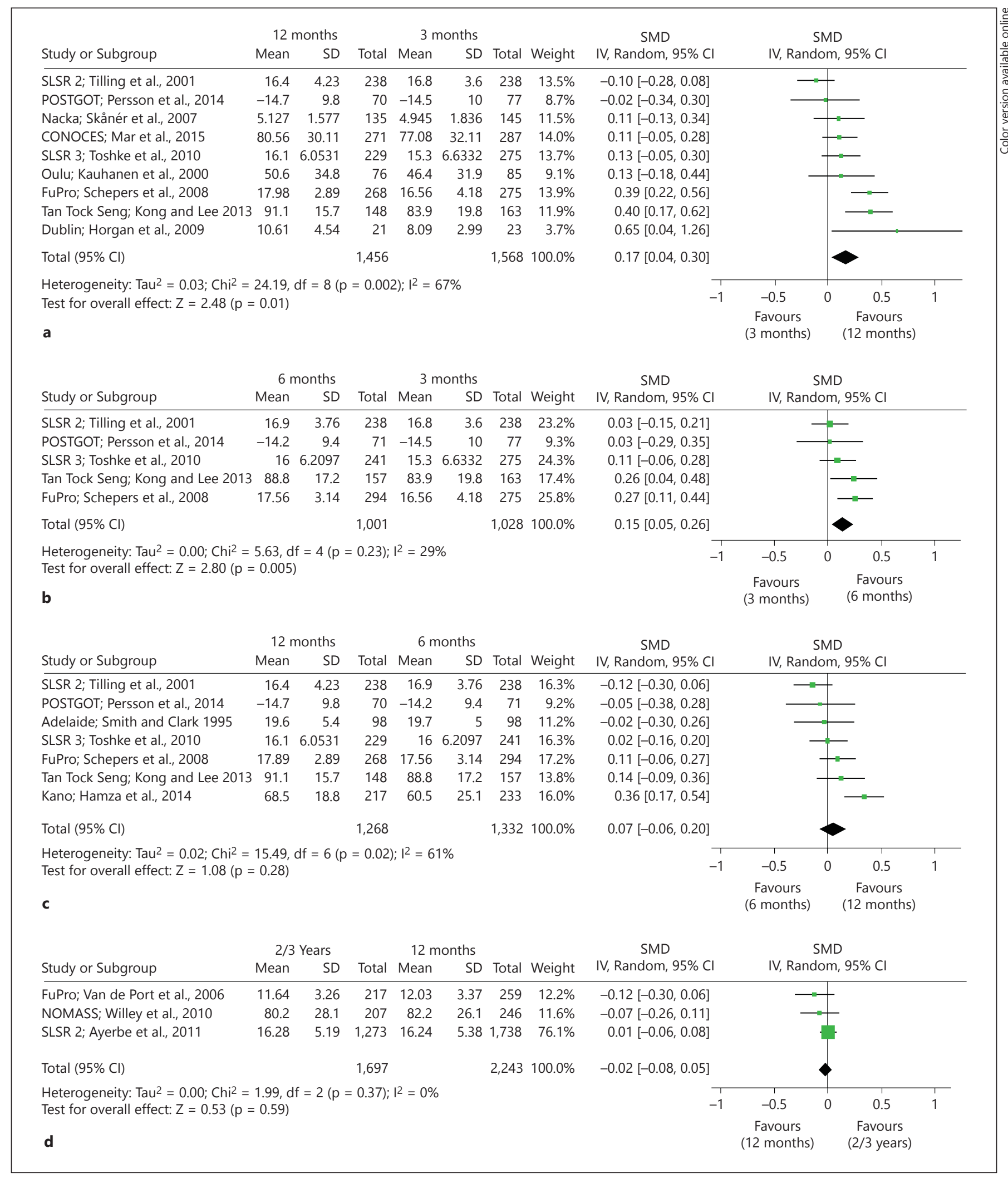

Fig. 2. SMD of the course of ADL between 3 and 12 months (a), 3 and 6 months (b), 6 and 12 months (c), 12 months and $2 / 3$ years $(\mathbf{d})$. A positive mean difference score indicates an improvement in ADL. $\mathrm{I}^{2}=$ Heterogeneity.

The Course of ADL-Status and Associations with Decline after Stroke
Cerebrovasc Dis 2017;43:1-8 DOI: $10.1159 / 000451034$ 
Table 2. Percentage of stroke population who declined, maintained or improved in ADL

\begin{tabular}{|c|c|c|c|c|}
\hline Author & Recruitment & Outcome measure & Time point & Improve/maintain/decline \\
\hline Wilkinson et al. [47], 1997 & Hospital & Barthel Index & 3 months to 5 years & $103(7 / 54 / 39)$ \\
\hline Persson et al. [35], 2014 & Hospital & Time up and go & $\begin{array}{l}3-6 \text { months } \\
6-12 \text { months }\end{array}$ & $\begin{array}{l}71(41 / 32 / 27) \\
67(36 / 22 / 42)\end{array}$ \\
\hline $\begin{array}{l}\text { FuPro study: } \\
\text { (1) Van Wijk et al. [46], } 2006 \\
\text { (2) Van de Port et al. [45], } 2006\end{array}$ & $\begin{array}{l}\text { Rehabilitation } \\
\text { center }\end{array}$ & Rivermead Mobility Index & $\begin{array}{l}\text { (1) } 1-2 \text { years } \\
\text { (2) } 1-3 \text { years }\end{array}$ & $\begin{array}{l}148(6.9 / 79.9 / 12.2) \\
202(7 / 72 / 21)\end{array}$ \\
\hline
\end{tabular}

Values are $n(\%)$.

Furthermore, studies reporting the proportion of the population that declines in ADL status suggest that 12 $40 \%$ of the patients decline in ADL status in the period between 3 months and the long-term post first-ever stroke. Although the reported percentages indicate considerable variation within the population, these percentages should be interpreted with caution due to the heterogeneity among these studies (e.g., in cutoff points, outcome measures and follow-up periods used). On the other hand, in a Swedish study 35,000 unselected stroke patients (both first-ever (81\%) and recurrent (19\%) were followed up at 3 and 12 months follow-up (ADL outcome was mobility, toilet and dressing). The study found a $16 \%$ decline among survivors, from a level of independence in ADL to a level of dependence in ADL [52]. Although these results are not generalizable to a population of patients with exclusively first-ever stroke, the findings of this study are in agreement with the findings from our review. For future research, it will be important to focus on clinical relevant decline in ADL status or decline from a level of independency to a level of dependency.

\section{Factors Associated with ADL Decline Over Time}

Only 5 studies were found describing 9 factors associated with decline in ADL status from 3 months after stroke and onward. When patients are dependent with respect to $\mathrm{ADL}$, they are at risk to decline further in their ADL status. Also, patients with impaired motor function of the leg (including impaired leg function [45] and paralysis of the leg [42]) seem to be at risk for decline in ADL status. Impaired $\mathrm{ADL}$ and motor function may contribute to a more physically inactivity lifestyle [53]. Physical inactivity in turn could result in a reduction in cardiorespiratory fitness and muscle strength, leading to a further decline in ADL status [53]. In the current study, although limited, evidence was found for the association between inactivity and decline in ADL status. However, inactivity was measured with the Frenchay Activities Index, which measures the self-perceived level of functional activities. Less is known about physical behavior, the amount of physical activity and sedentary time in the context of ADL status [54] in patients after stroke, especially with respect to long-term changes in ADL status [55]. Besides physical impairments other modifiable factors, such as cognitive function, depression and fatigue, might contribute to decline in ADL status as well and therefore should be addressed in future research.

\section{Study Limitations}

The most common source of bias in the included studies was attrition bias. Most studies recruited participants from a hospital setting, in which earlier research has shown relatively high mortality rates of $25 \%$ within the first year [56, 57]. Consequently, this might have biased our results, because patients with poor functional outcome have a higher short-term mortality risk, since poor outcome at 3 months is a strong predictor of death [58]. Because of the dropout of deceased patients in follow-up analyses, the results on the course in our review in the first year follow-up and onward might be an overestimation of the ADL status. Furthermore, on average, per year $10 \%$ of the participants in the included studies were lost to follow-up due to a variety of reasons. In most studies, a description of differences between completing participants and dropouts was lacking.

As mentioned earlier in the discussion, one of the limitations of our study was the heterogeneity of included stud- 
ies in patient population, ADL outcomes used different follow-up times and intervals, and different local treatment/ rehabilitation traditions. Unfortunately, due to the limited number of studies that could be included in the meta-analysis, not all relevant subgroup analyses could be performed. When we interpreted the heterogeneity, we found moderate to high heterogeneity between studies on the time course from 3 to 12 months. However, within the sub-analysis between 3 and 6 months, only a heterogeneity of $29 \%$ was found indicating limited to moderate heterogeneity. The heterogeneity can be explained because the hospitalbased population remained fairly stable whereas the rehabilitation populations still showed improvement. Within the sub-analysis between 6 and 12 months, the heterogeneity was mainly due to the study by Hamza et al. [24], which had a major effect on the heterogeneity. When excluding this study from the analysis, the heterogeneity declined to zero. However, the SMD remained non-significant but changed to $0.02(-0.07$ to 0.10$)$. The difference in study population might offer a possible explanation for the different results between this study and the others. The population in the study performed by Hamza et al. [24] was Nigerian, and the differences in healthcare systems between western countries and developing countries must not be underestimated [59].

\section{Conclusion}

Although patients do not seem to decline in ADL for up to 3 years, there is considerable variation within the population. Some modifiable factors associated with decline in ADL were identified. However, more research is needed before patients at risk of deterioration in ADL can be identified.

\section{Acknowledgments}

We express our gratitude to all authors of the included studies for providing additional information and/or data from their studies.

\section{Sources of Funding}

Netherlands Organization for Scientific Research.

\section{Disclosure Statement}

The authors have no conflicts of interest to declare.

\section{References}

1 Lopez AD, Mathers CD: Measuring the global burden of disease and epidemiological transitions: 2002-2030. Ann Trop Med Parasitol 2006; 100:481-499.

2 Feigin VL, Forouzanfar MH, Krishnamurthi R, Mensah GA, Connor M, Bennett DA, et al: Global and regional burden of stroke during 1990-2010: findings from the Global Burden of Disease Study 2010. Lancet 2014;383:245254.

3 Fisher A, Martin J, Srikusalanukul W, Davis M: Trends in stroke survival incidence rates in older Australians in the new millennium and forecasts into the future. J Stroke Cerebrovasc Dis 2014;23:759-770.

4 Krishnamurthi RV, Feigin VL, Forouzanfar MH, Mensah GA, Connor M, Bennett DA, et al: Global and regional burden of first-ever ischaemic and haemorrhagic stroke during 1990-2010: findings from the Global Burden of Disease Study 2010. Lancet Glob Health 2013;1:e259-e281.

5 Langhorne P, Bernhardt J, Kwakkel G: Stroke rehabilitation. Lancet 2011;377:1693-1702.

6 Stroke Unit Trialists' Collaboration: Organised inpatient (stroke unit) care for stroke. Cochrane Database Syst Rev 2013;9: CD000197.
7 Blömer AM, van Mierlo ML, Visser-Meily JM, van Heugten CM, Post MW: Does the frequency of participation change after stroke and is this change associated with the subjective experience of participation? Arch Phys Med Rehabil 2015;96:456463.

8 World Health Organization: How to Use the ICF: A Practical Manual for Using the International Classification of Functioning, Disability and Health (ICF). Exposure Draft for Comment. Geneva, WHO, 2013.

9 Moher D, Liberati A, Tetzlaff J, Altman DG: Preferred reporting items for systematic reviews and meta-analyses: the PRISMA statement. PLoS Med 2009;6:e1000097.

10 Veerbeek JM, van Wegen E, van Peppen R, van der Wees PJ, Hendriks E, Rietberg M, et al: What is the evidence for physical therapy poststroke? A systematic review and metaanalysis. PLoS One 2014;9:e87987.

11 Hayden JA, van der Windt DA, Cartwright JL, Côté P, Bombardier C: Assessing bias in studies of prognostic factors. Ann Intern Med 2013;158:280-286.

12 Cohen J: Statistical Power Analysis for the Behavioral Sciences. Statistical Power Analysis for the Behavioral Sciences, 1988.
13 Schepers VP, Ketelaar M, Visser-Meily JM, Dekker J, Lindeman E: Responsiveness of functional health status measures frequently used in stroke research. Disabil Rehabil 2006; 28:1035-1040.

14 Higgins JP, Thompson SG, Deeks JJ, Altman DG: Measuring inconsistency in meta-analyses. BMJ 2003;327:557-560.

15 Sackett DL, Straus SE, Richardson WS, Rosenberg W, Haynes RB: Evidence-Based Medicine: How to Practice and Teach EBM. Philadelphia, Chrurchill-Livingstone. 2000.

16 Appelros P, Samuelsson M, Lindell D: Lacunar infarcts: functional and cognitive outcomes at five years in relation to MRI findings. Cerebrovasc Dis 2005;20:34-40.

17 Ayerbe L, Ayis S, Rudd AG, Heuschmann PU, Wolfe CD: Natural history, predictors, and associations of depression 5 years after stroke: the South London stroke register. Stroke 2011;42:1907-1911.

18 Baert I, Vanlandewijck Y, Feys H, Vanhees L, Beyens H, Daly D: Determinants of cardiorespiratory fitness at 3,6 and 12 months poststroke. Disabil Rehabil 2012;34:1835-1842.

19 Callahan CD, Young PL, Barisa MT: Using the SF-36 for longitudinal outcomes assessment in rehabilitation. Rehabil Psychol 2005;50:65-70.
The Course of ADL-Status and Associations with Decline after Stroke
Cerebrovasc Dis 2017;43:1-8 DOI: $10.1159 / 000451034$ 
20 Dhamoon MS, Moon YP, Paik MC, BodenAlbala B, Rundek T, Sacco RL, et al: Longterm functional recovery after first ischemic stroke: the Northern Manhattan study. Stroke 2009;40:2805-2811.

21 Fukuda M, Kanda T, Kamide N, Akutsu T, Sakai F: Gender differences in long-term functional outcome after first-ever ischemic stroke. Intern Med 2009;48:967-973.

22 Gbiri CA, Akinpelu AO: Relationship between post-stroke functional recovery and quality of life among Nigerian stroke survivors. Niger Postgrad Med J 2013;20:29-33.

23 Gosman-Hedström G, Blomstrand C: Evaluation of a 5-level functional independence measure in a longitudinal study of elderly stroke survivors. Disabil Rehabil 2004;26: 410-418.

24 Hamza AM, Al-Sadat N, Loh SY, Jahan NK: Predictors of poststroke health-related quality of life in nigerian stroke survivors: a 1-year follow-up study. Biomed Res Int 2014;2014: 350281.

25 Harwood RH, Gompertz P, Pound P, Ebrahim S: Determinants of handicap 1 and 3 years after a stroke. Disabil Rehabil 1997;19: 205-211.

26 Horgan NF, O’Regan M, Cunningham CJ, Finn AM: Recovery after stroke: a 1-year profile. Disabil Rehabil 2009;31:831-839.

27 Kauhanen ML, Korpelainen JT, Hiltunen P, Nieminen P, Sotaniemi KA, Myllylä VV: Domains and determinants of quality of life after stroke caused by brain infarction. Arch Phys Med Rehabil 2000;81:1541-1546.

28 Knauft W, Chhabra J, McCullough LD: Emergency department arrival times, treatment, and functional recovery in women with acute ischemic stroke. J Womens Health (Larchmt) 2010;19:681-688.

29 Kong K, Lee J: Temporal recovery and predictors of activities of daily living in the first year after stroke: a prospective study of patients admitted to a rehabilitation unit. Int Psychogeriatr 2013;25:S130-S131.

30 Kotila M, Waltimo O, Niemi ML, Laaksonen $\mathrm{R}$, Lempinen $\mathrm{M}$ : The profile of recovery from stroke and factors influencing outcome. Stroke 1984;15:1039-1044.

31 Lo RS, Cheng JO, Wong EM, Tang WK, Wong LK, Woo J, et al: Handicap and its determinants of change in stroke survivors: oneyear follow-up study. Stroke 2008;39:148153.

32 Mar J, Masjuan J, Oliva-Moreno J, GonzalezRojas N, Becerra V, Casado MÁ, et al: Outcomes measured by mortality rates, quality of life and degree of autonomy in the first year in stroke units in Spain. Health Qual Life Outcomes 2015;13:36.

33 Medeiros CA, de Bruin PF, Paiva TR, Coutinho WM, Ponte RP, de Bruin VM: Clinical outcome after acute ischaemic stroke: the influence of restless legs syndrome. Eur J Neurol 2011;18:144-149.
34 Meyer S, Verheyden G, Brinkmann N, Dejaeger E, De Weerdt W, Feys H, et al: Functional and motor outcome 5 years after stroke Is equivalent to outcome at 2 months: follow-up of the collaborative evaluation of rehabilitation in stroke across Europe. Stroke 2015;46: 1613-1619.

35 Persson CU, Danielsson A, Sunnerhagen KS, Grimby-Ekman A, Hansson PO: Timed Up \& Go as a measure for longitudinal change in mobility after stroke - Postural Stroke Study in Gothenburg (POSTGOT). J Neuroeng Rehabil 2014;11:83.

36 Pillai A, Menon SK, Kumar S, Rajeev K, Kumar A, Panikar D: Decompressive hemicraniectomy in malignant middle cerebral artery infarction: an analysis of long-term outcome and factors in patient selection. J Neurosurg 2007;106:59-65.

37 Samuelsson M, Söderfeldt B, Olsson GB: Functional outcome in patients with lacunar infarction. Stroke 1996;27:842-846.

38 Schepers VP, Ketelaar M, Visser-Meily AJ, de Groot V, Twisk JW, Lindeman E: Functional recovery differs between ischaemic and haemorrhagic stroke patients. J Rehabil Med 2008;40:487-489.

39 Skånér Y, Nilsson GH, Sundquist K, Hassler E, Krakau I: Self-rated health, symptoms of depression and general symptoms at 3 and 12 months after a first-ever stroke: a municipality-based study in Sweden. BMC Fam Pract 2007;8:61.

40 Smith DS, Clark MS: Competence and performance in activities of daily living of patients following rehabilitation from stroke. Disabil Rehabil 1995;17:15-23.

41 Sturm JW, Dewey HM, Donnan GA, Macdonell RA, McNeil JJ, Thrift AG: Handicap after stroke: how does it relate to disability, perception of recovery, and stroke subtype? The North East Melbourne Stroke Incidence Study (NEMESIS). Stroke 2002;33:762-768.

42 Taub NA, Wolfe CD, Richardson E, Burney PG: Predicting the disability of first-time stroke sufferers at 1 year. 12-month follow-up of a population-based cohort in southeast England. Stroke 1994;25:352-357.

43 Tilling K, Sterne JAC, Rudd AG, Glass TA, Wityk RJ, Wolfe CDA: A new method for predicting recovery after stroke. Stroke 2001;32: 2867-2873.

44 Toschke AM, Tilling K, Cox AM, Rudd AG, Heuschmann PU, Wolfe CD: Patient-specific recovery patterns over time measured by dependence in activities of daily living after stroke and post-stroke care: the South London Stroke Register (SLSR). Eur J Neurol 2010;17:219-225.

45 Van de Port IG, Kwakkel G, van Wijk I, Lindeman E: Susceptibility to deterioration of mobility long-term after stroke: a prospective cohort study. Stroke 2006;37:167-671.
46 Van Wijk I, Algra A, Van De Port IG, Bevaart $\mathrm{B}$, Lindeman $\mathrm{E}$ : Change in mobility activity in the second year after stroke in a rehabilitation population: who is at risk for decline? Arch Phys Med Rehabil 2006;87:45-50.

47 Wilkinson PR, Wolfe CD, Warburton FG, Rudd AG, Howard RS, Ross-Russell RW, et al: A long-term follow-up of stroke patients. Stroke 1997;28:507-512.

48 Willey JZ, Disla N, Moon YP, Paik MC, Sacco RL, Boden-Albala B, et al: Early depressed mood after stroke predicts longterm disability: the Northern Manhattan Stroke Study (NOMASS). Stroke 2010;41: 1896-1900.

49 Nydevik I, Hulter-Asberg K: Sickness impact after stroke. A 3-year follow-up. Scand J Prim Health Care 1992;10:284-289.

50 Wolfe CD, Crichton SL, Heuschmann PU, McKevitt CJ, Toschke AM, Grieve AP, et al: Estimates of outcomes up to ten years after stroke: analysis from the prospective South London stroke register. PLoS Med 2011; 8:e1001033

51 Patel MD, Tilling K, Lawrence E, Rudd AG, Wolfe CD, McKevitt C: Relationships between long-term stroke disability, handicap and health-related quality of life. Age Ageing 2006;35:273-279.

52 Ullberg T, Zia E, Petersson J, Norrving B: Changes in functional outcome over the first year after stroke: an observational study from the Swedish stroke register. Stroke 2015;46: 389-394.

53 Saunders DH, Sanderson M, Brazzelli M, Greig CA, Mead GE: Physical fitness training for stroke patients. Cochrane database Syst Rev 2013;10:CD003316.

54 Bussmann JB, van den Berg-Emons RJ: To total amount of activity..... and beyond: perspectives on measuring physical behavior. Front Psychol 2013;4:463.

55 English C, Manns PJ, Tucak C, Bernhardt J: Physical activity and sedentary behaviors in people with stroke living in the community: a systematic review. Phys Ther 2014;94:185196.

56 Koton S, Tanne D, Green MS, Bornstein NM: Mortality and predictors of death 1 month and 3 years after first-ever ischemic stroke: data from the first national acute stroke Israeli survey (NASIS 2004). Neuroepidemiology 2010;34:90-96.

57 Hankey GJ: Long-term outcome after ischaemic stroke/transient ischaemic attack. Cerebrovasc Dis 2003;16(suppl 1):14-19.

58 Andersen KK, Olsen TS, Dehlendorff C, Kammersgaard LP: Hemorrhagic and ischemic strokes compared: stroke severity, mortality, and risk factors. Stroke 2009;40:20682072.

59 Brainin M, Teuschl Y, Kalra L: Acute treatment and long-term management of stroke in developing countries. Lancet Neurol 2007;6: 553-561. 